\title{
Consumo e digestibilidade de novilhos Nelore sob pastagem suplementados com misturas múltiplas
}

[Intake and digestibility of Nelore steers grazing pasture and supplemented with multiple mixture]

\author{
L.O.F. Oliveira ${ }^{1 *}$, E.O.S. Saliba ${ }^{2}$, N.M. Rodriguez ${ }^{2}$, L.C. Gonçalves $^{2}$, I. Borges ${ }^{2}$, T.B. Amaral ${ }^{3}$ \\ ${ }^{1}$ Aluno de Doutorado em Ciência Animal da UFMG - Belo Horizonte, MG \\ ${ }^{2}$ Escola de Veterinária da UFMG - Belo Horizonte, MG \\ ${ }^{3}$ EMBRAPA / Gado de Corte - Campo Grande, MS
}

\begin{abstract}
RESUMO
Estudou-se o efeito da suplementação com misturas múltiplas sobre o consumo, digestibilidade e desempenho de novilhos Nelore, em pastagens de Brachiaria brizantha $\mathrm{Cv}$. Marandu, submetidos a quatro tratamentos. No tratamento um (T1), cada animal recebeu $800 \mathrm{~g} /$ dia de suplemento contendo uréia como fonte de nitrogênio não protéico (NNP); no tratamento dois (T2), recebeu $800 \mathrm{~g} /$ dia de mistura na qual a uréia foi substituída por amiréia como fonte de NNP; no tratamento três (T3), recebeu 1500g/dia de uma mistura com amiréia; e no tratamento quatro (T4= controle), recebeu sal mineral. Seis animais por tratamento foram utilizados para se medir o consumo pela técnica de indicador externo (óxido crômico), e 10 animais foram usados na avaliação de ganho de peso. Foram utilizados dois animais canulados no esôfago para coleta de amostra de extrusa. Os animais suplementados obtiveram ganhos de peso superiores $(\mathrm{P}<0,05)$ aos do tratamento-controle, 435, 419, 467 e $271 \mathrm{~g} /$ dia para os tratamentos T1, T2, T3 e T4, respectivamente. Os coeficientes de digestibilidade da matéria seca (MS) foram de 56,7, 49,8, 48,9 e 45,5\% para os tratamentos T1, T2, T3 e T4, respectivamente, sendo correlacionados positivamente com a digestibilidade in vitro da MS $(\mathrm{P}<0,05)$. A suplementação com misturas múltiplas promoveu aumento no consumo $(\mathrm{P}<0,05)$.
\end{abstract}

Palavras-chave: bovino, amiréia, mistura múltipla, suplementação

\begin{abstract}
The effect of three multiple mixtures supplementation on intake, digestibility and performance of Nelore steers grazing pasture of Brachiaria decumbens $C V$ Marandu was studied. The multiple mixtures (treatments - T) were defined as: T1 - 800g of supplement with urea as crude protein source, T2 - $800 \mathrm{~g}$ of mixture in which urea was replaced by starea, T3 - 1500g of starea, and T4 - mineral salt fed ad libitum as a control group. Six animals per treatment were given chromic oxide as a marker to measure intake and 10 animals per treatment were used to evaluate their performance. Two esophageal fistulated steers were used to collect samples of extruse. The animals fed on supplement diets showed higher weight gains (335, 419, 467g/animal) than those from the control group (271g/animal). Dry matter digestibility were 56.7, 49.8, 48.9 and 45.5\%, respectively, for T1, T2, T3 and T4. A positive correlation between dry matter digestibility and in vitro dry matter digestibility $(P<0.05)$ was observed. Supplementation with multiple mixtures increased dry matter intake $(P<0.05)$.
\end{abstract}

Keywords:cattle, multiple mixture, supplementation, starea

Pesquisa parcialmente financiada pelo $\mathrm{CNPq}$

Recebido para publicação em 9 de novembro de 2002

Recebido para publicação, após modificações, em 17 de agosto de 2003

*Endereço para correspondência:

Rua Amazonas, 1567

79022-130, Campo Grande, MS

E-mail: luizorcirio@hotmail.com 


\section{Oliveira et al.}

\section{INTRODUÇÃO}

Durante o período chuvoso do ano, as pastagens tropicais da região Centro-Sul do Brasil apresentam taxas elevadas de crescimento e melhor valor nutricional quando comparadas com as do período seco. Euclides (1997), acompanhando o efeito climático sobre o valor nutricional de pastagens de Brachiaria brizantha CV Marandu, observou que o teor de proteína bruta (PB) e a digestibilidade in vitro da matéria orgânica diminuíram de $9,3 \%$ e $61,2 \%$ para $6,2 \%$ e $51,5 \%$, respectivamente, do período chuvoso para o seco do ano.

Bovinos alimentando-se em pastagem com teor de $\mathrm{PB}$ inferior a $7 \%$ são incapazes de manter o nível mínimo de $8 \mathrm{mg} / \mathrm{dl}$ de nitrogênio amoniacal $\left(\mathrm{N}-\mathrm{NH}_{3}\right)$ necessário para manter o crescimento das bactérias celulolíticas, reduzindo assim a atividade digestiva e o consumo. Pequenas quantidades de energia e $\mathrm{N}$ prontamente solúveis podem aumentar a digestão da forragem de baixa qualidade e, em alguns casos, o seu consumo (Egan, Doyle, 1985).

Uma das limitações do uso da uréia pelos ruminantes é atribuída à sua elevada solubilidade no rúmen, o que a transforma muito rapidamente em amônia devido à ação da enzima urease produzida pelos microrganismos ruminais (Owens, Zinn, 1988; Reynolds, 1992). Dessa forma, suplementos contendo elevados níveis de uréia como fonte de NNP liberam alta concentração de $\mathrm{N}_{-} \mathrm{NH}_{3}$ no rúmen, que pode não ser convertida em proteína microbiana devido a insuficiência em carboidratos prontamente solúveis (Minson, 1990).

Os carboidratos estruturais das forragens são as principais fontes de energia para animais em pasto, porém são menos susceptíveis à hidrólise do que os polímeros de amido e as xilanas. Quando submetidos a um meio acidificado $(1,0 \mathrm{~N})$ por três horas, as xilanas tornam-se solúveis em temperatura de $25^{\circ} \mathrm{C}$, enquanto que a celulose requer temperaturas superiores a $100^{\circ} \mathrm{C}$ (Van Soest, 1994).

A amônia presente no rúmen, e não incorporada à massa microbiana, será posteriormente absorvida para a corrente sangüínea e eliminada pela urina. Esse processo metabólico é indesejável, pois requer o uso de energia que poderia ser utilizada para a produção (Thiago, 1998).

Processos físicos como a extrusão, que une a uréia à molécula do amido gelatinizado, podem acarretar efeitos positivos ao permitir a hidrólise mais lenta da uréia, tornando-a compatível com a energia disponível e permitindo aos microrganismos do rúmen síntese contínua de proteína celular (Cass et al., 1994; Parré, 1995).

Helmer (1970), em um experimento in vitro utilizando starea (amiréia) como substrato, observou concentrações maiores de proteína e menores de amônia no fluído ruminal, conseqüência do aumento na eficiência dos microrganismos na produção de proteínas.

O objetivo deste trabalho foi testar diferentes níveis de suplementação com misturas múltiplas (MM) sobre o consumo e a digestibilidade, e comparar o desempenho de novilhos suplementados com MM contendo uréia ou amiréia como fonte de NNP.

\section{MATERIAL E MÉTODOS}

Conduzido na Fazenda Rancho Alegre, Campo Grande - MS, no período de 2 de abril a 26 de setembro de 2001, o experimento foi implantado em área de 25 hectares, dividida em quatro piquetes de 6,25 hectares, formada de Brachiaria brizantha CV Marandu.

Usaram-se quarenta machos Nelore com aproximadamente 24 meses de idade, de modo a garantir média de peso vivo aproximada $(373,8$ $\mathrm{kg}$ ) entre os tratamentos (suplementação). Os animais receberam os seguintes tratamentos $(\mathrm{T})$ : $\mathrm{T} 1=800 \mathrm{gramas} /$ dia/cabeça da mistura múltipla 1 (MM1) com uréia; T2=800gramas/dia/cabeça da mistura múltipla 2 (MM2) com amiréia; T3= 1500 gramas/dia/cabeça, da mistura múltipla 3 (MM3) com amiréia; e T4= sal mineral recria (SMR) à vontade, contendo 72 gramas de fósforo/kg da mistura.

A suplementação foi diária em cochos sem cobertura. O suplemento foi oferecido uma única vez ao dia e sempre no mesmo horário (5h). A composição das MM e do sal mineral (SMR) são apresentadas na Tab. 1. 
Consumo e digestibilidade de novilhos Nelore...

Tabela 1. Composição das misturas múltiplas e do sal mineral recria para novilhos Nelore

\begin{tabular}{|c|c|c|c|c|}
\hline \multirow{2}{*}{ Ingrediente } & \multicolumn{4}{|c|}{ Suplemento } \\
\hline & Mistura múltipla 1 & Mistura múltipla 2 & Mistura múltipla 3 & Sal mineral recria \\
\hline Milho (\%) & 36,8 & 23,7 & 39,6 & 1,0 \\
\hline Melaço (\%) & - & - & - & 2,0 \\
\hline Farelo de soja (\%) & 36,4 & 33,4 & 32,9 & - \\
\hline Amiréia $^{1}(\%)$ & - & 23,6 & 16,7 & - \\
\hline Uréia pecuária $^{2}(\%)$ & 7,5 & - & - & - \\
\hline Fosfato bicálcico (\%) & 5,0 & 5,0 & 2,6 & 38,0 \\
\hline $\operatorname{Minerpac}^{3}(\%)$ & 1,3 & 1,3 & 0,7 & 8,0 \\
\hline Caulim & - & - & - & 2,0 \\
\hline Enxofre ventilado & 0,2 & 0,2 & 0,1 & - \\
\hline Calcita $(\%)$ & 2,3 & 2,3 & 1,7 & 15,0 \\
\hline Cloreto de sódio (\%) & 10,5 & 10,5 & 5,7 & 34,0 \\
\hline Total (\%) & 100 & 100 & 100 & 100 \\
\hline
\end{tabular}

$\mathrm{Na}$ formulação dos suplementos procurou-se oferecer quantidades de proteína degradável suficientes para atender o déficit desse nutriente em condições de pastejo no período seco do ano, a partir do teor de PB $(6,2 \%)$ e da digestibilidade $(51,5 \%)$ da Brachiaria brizantha CV Marandu, conforme dados de Euclides (1997).

Foram preparados dois animais com fístula esofagiana, de acordo com a técnica citada por Cook et al.(1958), os quais foram utilizados na colheita do material selecionado na dieta (extrusa).

Os animais foram pesados a cada 35 dias sempre após jejum de 12 horas.

O método do rendimento comparativo descrito por Haydock e Shaw (1975) foi aplicado para avaliar a disponibilidade de massa dos piquetes. Para controlar o efeito da disponibilidade de forragem entre piquetes foi adotado o método da taxa de lotação variável descrito por Mott e Lucas (1952).

As amostras de extrusa, transportadas em caixas térmicas para o laboratório de nutrição animal, foram armazenadas em câmara fria a $-17^{\circ} \mathrm{C}$ para posteriores análises. Para se estimar a produção fecal utilizou-se o óxido crômico como indicador externo, fornecido diariamente às 15 horas em dose única de 10 gramas.
As fezes foram colhidas uma vez ao dia no momento da administração do indicador, diretamente da ampola retal, a partir do oitavo dia do início do fornecimento do indicador e armazenadas em câmara fria à $-17^{\circ} \mathrm{C}$. O preparo das amostras de fezes seguiu a rotina para experimentos dessa natureza.

Segundo AOAC International (Cuniff, 1995), foram determinados os teores de matéria seca (MS), proteína bruta (PB), estado etéreo (EE), fibra bruta (FB), matéria mineral, estrato não nitrogenado (ENN), cálcio e fósforo. A determinação da fibra detergente neutro (FDN) e fibra detergente ácida (FDA) seguiu o método descrito por Robertson e Van Soest (1981). A digestibilidade da extrusa e das MM foram determinadas pelo método da digestibilidade in vitro descrito por Tilley e Terry (1963).

As amostras de fezes também foram analisadas por espectrofotometria de absorção atômica (EAA) para dosagem de cromo, conforme Williams et al. (1962), com modificações sugeridas por Saliba et al. (1999).

A excreção fecal foi estimada segundo Prigge et al. (1981). O coeficiente de digestibilidade da matéria seca (CDMS) foi calculado a partir dos valores de lignina da forragem, da MM proporcionalmente à oferta e das fezes (Aroeira, 1997). Para os cálculos do consumo de PB, FDN e FDA utilizou-se a relação proposta por Sniffen et al.(1992). 


\section{Oliveira et al.}

O consumo médio de sal mineral foi de 86 gramas/animal/dia. A Tab. 2 apresenta a composição química das misturas múltiplas, calculada a partir dos ingredientes utilizados, conforme tabela de alimentos citada por Valadares Filho (2000).

Tabela 2. Composição química calculada das misturas múltiplas ${ }^{1}$ oferecidas aos novilhos Nelore

\begin{tabular}{lccc}
\hline & \multicolumn{3}{c}{ Suplemento } \\
\cline { 2 - 4 } & $\begin{array}{c}\text { Mistura } \\
\text { múltipla 1 }\end{array}$ & $\begin{array}{c}\text { Mistura } \\
\text { múltipla 2 }\end{array}$ & $\begin{array}{c}\text { Mistura } \\
\text { múltipla 3 }\end{array}$ \\
\hline MS (\%) & 91,2 & 91,3 & 90,1 \\
Proteína bruta (\%) & 43,3 & 41,4 & 36,3 \\
NDT (\%) & 60,2 & 56,6 & 67,3 \\
EM (Mcal $/ \mathrm{kg})^{2}$ & 2,176 & 2,041 & 2,428 \\
\hline${ }^{1}$ Conforme Valadares Filho (2000) \\
${ }^{2}$ EM = Energia metabolizável estimada segundo NRC (1996).
\end{tabular}

O delineamento experimental utilizado foi inteiramente ao acaso, com quatro tratamentos e 10 repetições por tratamento para peso e ganho de peso, e seis repetições por tratamento para consumo. Os resultados foram comparados pelo teste SNK ao nível de 5\% de probabilidade pelo modelo SAEG (Sistema..., 1995). As correlações entre as variáveis foram calculadas conforme recomendação de Sampaio (1998).

\section{RESULTADOS E DISCUSSÃO}

A disponibilidade de MS dos piquetes durante o período experimental sempre esteve acima de 2000kg por hectare (Tab. 3). Segundo Hodgson (1990) e Minson (1990), a disponibilidade de MS somente afeta o consumo voluntário dos animais quando for inferior a essa quantidade.

Tabela 3. Disponibilidade de forragem ( $\mathrm{kg}$ de $\mathrm{MS} / \mathrm{ha}$ ) por piquete e por tratamento durante os meses de abril a setembro de 2001

\begin{tabular}{lcccc}
\hline & Piquete 1 & Piquete 2 & Piquete 3 & Piquete 4 \\
\hline Abril & 6065,2 & 5933,6 & 5731,8 & 5742,9 \\
Maio & 4582,7 & 4797,8 & 4628,3 & 4646,1 \\
Junho & 3936,4 & 3897,7 & 3842,0 & 3951,1 \\
Julho & 3116,6 & 3211,9 & 3063,0 & 3056,3 \\
Agosto & 2614,6 & 2562,5 & 2564,2 & 2468,2 \\
Setembro & 2172,3 & 2108,0 & 2071,9 & 2030,5 \\
& $\mathrm{~T} 1$ & $\mathrm{~T} 2$ & $\mathrm{~T} 3$ & $\mathrm{~T} 4$ \\
Média $(\mathrm{kg} / \mathrm{ha})^{1}$ & 3758,7 & 3700,2 & 3693,1 & 3646,3 \\
\hline
\end{tabular}

$\mathrm{T} 1=800 \mathrm{~g} /$ dia da mistura múltipla $1 \mathrm{com}$ uréia; $\mathrm{T} 2=800 \mathrm{~g} /$ dia da mistura 2 com amiréia; $\mathrm{T} 3=1500 \mathrm{~g} /$ dia da mistura múltipla $3 \mathrm{com}$ amiréia; $\mathrm{T} 4=$ sal mineral recria

${ }^{1} \mathrm{CV}=33,2 \%$.

$\mathrm{Na}$ análise química das amostras mensais de extrusa (Tab. 4) foi observado aumento nos teores de FDN e FDA, e redução nos teores de PB e de DIVMS a partir da primeira (abril) até a última coleta (setembro) do experimento. $\mathrm{O}$ baixo teor de proteína e o alto grau de lignificação podem ter limitado a digestibilidade de extrusa. Fike et al. (1995) consideram a suplementação protéica uma alternativa interessante, entretanto ressaltam que o nível ideal de suplementação de proteína ainda não está bem definido.

O coeficiente de digestibilidade da MS do T4 $(45,5 \%)$ foi o que mais se aproximou da DIVMS $(45,3 \%)$, calculada a partir da composição da extrusa. Observou-se correlação positiva de 0,78 $(\mathrm{P}<0,05)$ entre DIVMS e consumo de PB (Tab. 5), demonstrando a importância do consumo de proteína para a eficiência microbiana em dietas de baixo valor nutricional. 
Consumo e digestibilidade de novilhos Nelore...

Tabela 4. Composição química em base de matéria seca e digestibilidade in vitro da matéria seca da extrusa, colhida durante os meses de abril a setembro de 2001

\begin{tabular}{lcccccc}
\hline & \multicolumn{7}{c}{ Extrusa } \\
\cline { 2 - 6 } & Abril & Maio & Junho & Julho & Agosto & Setembro \\
\hline Matéria seca (\%) & 28,5 & 45,2 & 47,3 & 48,9 & 49,3 & 48,2 \\
Proteína bruta (\%) & 8,2 & 7,4 & 6,7 & 5,2 & 6,8 & 6,6 \\
Extrato etéreo (\%) & 2,8 & 2,0 & 2,2 & 2,2 & 2,3 & 2,2 \\
Fibra bruta (\%) & 36,5 & 37,8 & 38,3 & 38,5 & 44,5 & 40,2 \\
Extrato não nitrogenado (\%) & 46,6 & 46,9 & 47,3 & 48,6 & 41,1 & 45,6 \\
Minerais (\%) & 5,9 & 5,9 & 5,5 & 5,5 & 5,3 & 5,4 \\
Fibra detergente neutro (\%) & 75,5 & 77,3 & 78,3 & 80,4 & 79,5 & 78,0 \\
Fibra detergente ácido (\%) & 40,4 & 42,6 & 41,5 & 44,6 & 48,4 & 48,7 \\
Lignina (\%) & 3,9 & 4,6 & 5,1 & 6,0 & 6,5 & 5,2 \\
DIVMS (\%) & 47,5 & 46,3 & 44,6 & 41,3 & 41,5 & 45,3 \\
Cálcio (\%) & 0,41 & 0,45 & 0,38 & 0,39 & 0,35 & 0,38 \\
Fósforo (\%) & 0,19 & 0,12 & 0,11 & 0,11 & 0,10 & 0,12 \\
\hline
\end{tabular}

${ }^{\mathrm{T}} \mathrm{DIVMS}=$ digestibilidade in vitro da matéria seca.

Tabela 5. Coeficientes de digestibilidade da matéria seca da proteína bruta e da fibra detergente neutro e suas correlações com a digestibilidade in vitro da matéria seca, segundo os tratamentos

\begin{tabular}{lccccc}
\hline & T1 & T2 & T3 & T4 & Correlação \\
\hline Matéria seca (\%) & $56,73 \mathrm{a}$ & $49,78 \mathrm{a}$ & $48,91 \mathrm{a}$ & $45,53 \mathrm{~b}$ & $0,4780(\mathrm{~S})$ \\
Proteína bruta (\%) & 48,43 & 42,85 & 38,48 & 32,63 & $0,7782(\mathrm{~S})$ \\
Fibra detergente neutro (\%) & 56,73 & 49,78 & 47,91 & 45,53 & $0,3164(\mathrm{NS})$ \\
\hline
\end{tabular}

S: Correlação de Pearson significativa $(\mathrm{P}<0,05)$; NS: Correlação de Pearson não significativa $(\mathrm{P}>0,05)$.

CDMS $(\%)=100-\{100 \times$ (Lignina na extrusa / Lignina nas fezes) $\}$

Médias com letras iguais na mesma linha não diferem pelo teste SNK ( $\mathrm{P}>0,05)$.

$\mathrm{T} 1=800 \mathrm{~g} /$ dia da mistura múltipla 1 com uréia; $\mathrm{T} 2=800 \mathrm{~g} /$ dia da mistura $2 \mathrm{com}$ amiréia; $\mathrm{T} 3=1500 \mathrm{~g} /$ dia da mistura múltipla $3 \mathrm{com}$ amiréia; $\mathrm{T} 4=$ sal mineral recria.

Os coeficientes de digestibilidade da MS de T1, T2 e T3 foram superiores $(\mathrm{P}<0,05)$ ao de digestibilidade de T4. Penning et al. (1991) observaram que o mecanismo de enchimento é o principal fator no ajuste do consumo em dietas à base de forragens e que, em geral, à medida que aumenta o valor nutritivo, há elevação no consumo até o ponto estabelecido pela demanda fisiológica, nem sempre alcançado.
Os cálculos dos consumos de MS, PB, FDN e FDA, apresentados nas Tab. 6 e 7, foram estimados a partir das amostras de fezes e da extrusa colhidas durante o mês de setembro. Os consumos de MS em T1, T2 e T3 não diferiram entre si $(\mathrm{P}>0,05)$, no entanto o consumo no T4 foi inferior aos consumos de MS em T1 e T3 $(\mathrm{P}<0,05)$.

Tabela 6. Consumo diário de matéria seca (MS) e de proteína bruta (PB), de acordo com o tratamento experimental $(\mathrm{T})$

\begin{tabular}{lccccc}
\hline & T1 & T2 & T3 & T4 & CV $(\%)$ \\
\hline $\mathrm{kg} /$ dia & & & Consumo de MS & $7,07 \mathrm{~b}$ & 19,03 \\
\% do peso vivo & $8,96 \mathrm{a}$ & $8,15 \mathrm{ab}$ & $8,89 \mathrm{a}$ & $1,71 \mathrm{~b}$ & 20,42 \\
$\mathrm{~g} / \mathrm{kg}^{0,75}$ & $2,23 \mathrm{a}$ & $1,98 \mathrm{ab}$ & $2,17 \mathrm{a}$ & $77,13 \mathrm{~b}$ & 20,03 \\
& $99,79 \mathrm{a}$ & $89,30 \mathrm{ab}$ & $98,10 \mathrm{a}$ & \\
$\mathrm{kg} / \mathrm{dia}$ & & $0,733 \mathrm{~b}$ & $0,927 \mathrm{a}$ & $0,405 \mathrm{c}$ & 12,73 \\
$\mathrm{~g} / \mathrm{kg}^{0,75}$ & $0,795 \mathrm{~b}$ & $8,03 \mathrm{~b}$ & $10,20 \mathrm{a}$ & $4,42 \mathrm{c}$ & 13,75 \\
\hline
\end{tabular}

Médias com letras iguais na mesma linha não diferem pelo teste SNK $(\mathrm{P}>0,05)$.

$\mathrm{T} 1=800 \mathrm{~g} /$ dia da mistura múltipla $1 \mathrm{com}$ uréia; $\mathrm{T} 2=800 \mathrm{~g} /$ dia da mistura $2 \mathrm{com}$ amiréia; $\mathrm{T} 3=1500 \mathrm{~g} /$ dia da mistura múltipla $3 \mathrm{com}$ amiréia; $\mathrm{T} 4=$ sal mineral recria. 


\section{Oliveira et al.}

Tabela 7. Consumo diário das frações fibrosas calculado a partir da extrusa e da mistura múltipla, de acordo com o tratamento experimental

\begin{tabular}{lccccc}
\hline & $\mathrm{T} 1$ & $\mathrm{~T} 2$ & $\mathrm{~T} 3$ & $\mathrm{~T} 4$ & $\mathrm{CV}(\%)$ \\
\hline $\mathrm{kg} / \mathrm{dia}$ & & & Consumo de FDN & & \\
$\mathrm{g} / \mathrm{kg} \mathrm{peso} \mathrm{vivo}^{0,61 \mathrm{a}}$ & $16,42 \mathrm{a}$ & $5,99 \mathrm{a}$ & $6,18 \mathrm{a}$ & $5,54 \mathrm{a}$ & 20,51 \\
$\mathrm{~g} / \mathrm{kg}^{0,75}$ & $73,56 \mathrm{a}$ & $15,13 \mathrm{a}$ & $13,40 \mathrm{a}$ & 21,89 \\
& $73,54 \mathrm{a}$ & $65,58 \mathrm{a}$ & $68,03 \mathrm{a}$ & $60,41 \mathrm{a}$ & 21,51 \\
$\mathrm{~kg} / \mathrm{dia}$ & $4,23 \mathrm{a}$ & $3,82 \mathrm{a}$ & Consumo de FDA & & \\
$\mathrm{g} / \mathrm{kg}^{0,75}$ & $47,11 \mathrm{a}$ & $41,87 \mathrm{a}$ & $3,93 \mathrm{a}$ & $3,55 \mathrm{a}$ & 20,58 \\
\hline
\end{tabular}

Médias com letras iguais na mesma linha não diferem pelo teste SNK $(\mathrm{P}>0,05)$.

$\mathrm{T} 1=800 \mathrm{~g} /$ dia da mistura múltipla $1 \mathrm{com}$ uréia; T2=800g/dia da mistura $2 \mathrm{com}$ amiréia; T3=1500g/dia da mistura múltipla $3 \mathrm{com}$ amiréia; T4= sal mineral recria.

Ao testarem vários níveis de suplementação em novilhos Nelore, Ladeira et al. (1999) observaram consumo médio de MS de $1,97 \%$ do $\mathrm{PV}$, valor superior ao observado no tratamento T4 (1,7\%), mas inferior aos observados em T1, T2 e T3 (2,2, 2,0 e 2,2\%). Euclides et al. (1999), ao testarem animais em pastagens de gramíneas do gênero Panicum $s p$ e que receberam apenas mistura mineral, observaram consumo de MS de $2,8 \%$ do PV e de $2,1 \%$ do PV durante os períodos chuvoso e seco do ano, respectivamente.

O consumo de PB (Tab.6) foi maior em T3 $(\mathrm{P}<0,05)$. T1 e T2 não diferiram entre si $(\mathrm{P}>0,05)$, porém também foram superiores ao T4 $(\mathrm{P}<0,05)$.

O consumo de MS a partir da média dos quatro tratamentos foi de $8,26 \mathrm{~kg} /$ dia. Para otimizar o funcionamento do rúmen e não prejudicar o consumo seria necessária, segundo Egan e Doyle (1985), a ingestão de $0,578 \mathrm{~kg}$ de $\mathrm{PB}$ por dia $(8,26 \mathrm{~kg}$ de $\mathrm{MS} \times 7,0 \% \mathrm{~PB})$. O consumo de $\mathrm{PB}$ em T1, T2 e T3 foi superior a essa recomendação, e no T4 foi inferior, o que pode ter reduzido a eficiência de degradação dos alimentos no rúmen, tendo por base esses autores.

Segundo Mertens (1994), a ingestão de FDN maior que $12 \mathrm{~g} / \mathrm{kg} \mathrm{PV}$ constitui a maneira quantitativa de se identificar o limite do consumo pelo enchimento do rúmen (mecanismo físico). No entanto, Euclides et al.(1999), ao trabalharem com pastagens do gênero Panicum sp., observaram consumo médio de $14,5 \mathrm{~g} / \mathrm{kg}$ PV. Os consumos médios de FDN observados neste experimento (Tab.7) variaram de $16,42 \mathrm{~g} / \mathrm{kg} \mathrm{PV}$ em T1 a 13,40g/kg PV em T4.

Considerando-se a média aritmética dos consumos de T1 a T4 (14,8g/kg PV), observa-se semelhança com os dados encontrados por Euclides et al. (1999). Dessa forma, apesar de os experimentos terem usado espécies forrageiras diferentes, os dois resultados são um indicativo de que os parâmetros de degradabilidade da FDN de forragens tropicais podem ser diferentes dos de forragens temperadas. As médias de consumo de FDN e FDA não diferiram segundo os tratamentos $(\mathrm{P}<0,05)$.

Não foram observadas diferenças entre T1 e T2 quanto ao ganho de peso $(\mathrm{P}<0,05)$. Dessa forma, os resultados obtidos nas condições deste trabalho sugerem que na suplementação com animais em pasto, os maiores problemas de utilização da uréia podem estar associados às suas toxicidade e baixa palatabilidade.

Pelas análises da extrusa (Tab. 4) observou-se redução no teor de $\mathrm{PB}$ e aumento nos teores de FDN, FDA e lignina. Dessa forma, acredita-se que a suplementação pode ter complementado o déficit da forragem, permitindo maior ganho de peso (Tab. 8) para os animais suplementados (T1, T2 e T3) em relação aos não suplementados (T4) $(\mathrm{P}<0,05)$. 
Tabela 8. Peso e ganho de peso diário (GPD) de novilhos Nelore, de acordo com o tratamento experimental

\begin{tabular}{|c|c|c|c|c|c|}
\hline & $\mathrm{T} 1$ & $\mathrm{~T} 2$ & T3 & $\mathrm{T} 4$ & CV (\%) \\
\hline Peso (kg) & $404,50 \mathrm{a}$ & $409,58 \mathrm{a}$ & $407,89 a$ & $397,4 a$ & 6,59 \\
\hline GPD (kg/dia) & $0,4354 \mathrm{a}$ & $0,4193 \mathrm{a}$ & $0,4675 \mathrm{a}$ & $0,271 \mathrm{~b}$ & 48,57 \\
\hline
\end{tabular}

Paulino et al. (2001) explicou que os resultados econômicos da atividade são melhores quando o ganho compensatório é explorado adequadamente nos animais em crescimento. Para tanto, os animais que estariam sofrendo restrição alimentar durante o período seco não deveriam perder peso e sim manter o ganho ao redor de 200 a $300 \mathrm{~g} /$ dia, o que justificaria o uso das misturas múltiplas de baixo consumo.

A resposta à suplementação depende de fatores intrínsecos aos animais como sexo, idade, genética etc., e de fatores ambientais como clima, valor nutricional e disponibilidade das pastagens, tamanho do rebanho etc. Não houve diferenças de ganho de peso $(\mathrm{P}>0,05)$ entre $\mathrm{T} 1$, T2 e T3, sugerindo que o fornecimento de misturas múltiplas na quantidade de 800 gramas/cab/dia foi eficiente.

\section{CONCLUSÕES}

A suplementação de novilhos Nelore com misturas múltiplas em pastagens de Brachiaria brizantha CV Marandu promoveu aumento no consumo e no ganho de peso diário quando comparada à suplementação apenas com mistura mineral. A substituição de uréia pela amiréia ou o aumento da suplementação de $800 \mathrm{~g}$ para $1500 \mathrm{~g} / \mathrm{cab} /$ dia não promoveram diferenças no consumo e no desempenho de novilhos Nelore sob pastejo.

\section{REFERÊNCIAS BIBLIOGRÁFICAS}

AROEIRA, L.J.M. Estimativas de consumo de gramíneas tropicais. In: TEIXEIRA, J.C. (Ed.) SIMPÓSIO INTERNACIONAL DE DIGESTIBILIDADE EM RUMINANTES, 1997, Lavras : UFLA-FAEPE, 1997. p.127-163.
CASS, J.L.; RICHARDSON, C.R.; SMITH, K.J. Evaluation of slow ammonia release from urea/calcium compounds. J. Anim. Sci., v.72, p.234 (suppl.1), 1994.

COOK, C.W.; THORNE, J.L.; BLAKE, J.T. et al. Use of an esophageal fistula cannula forage for collecting forage samples by grazing sheep. J. Anim. Sci., v.17, p.189-193, 1958.

CUNNIFF, P. (Ed.). Official methods of analysis of AOAC International. 16.ed. Arlington:AOAC International, 1995, v.1

EGAN, J.K.; DOYLE, P.T. Effect of intraruminal infusion of urea on the response in voluntary feed intake by sheep. Austr. J. Agric. Res., v.36, p.483-495, 1985.

EUCLIDES, V.P.B. Desempenho animal em pastagens. In: Curso de pastagens (1997). Campo Grande:EMBRAPA-CNPGC, 1997.

EUCLIDES, V.P.B.; THIAGO, L.R.L.S.; MACEDO, M.C.M. et al. Consumo voluntário de forragem de três cultivares de Panicum maximum sob pastejo. Rev. Bras. Zootec., v.28, p.1177-1185, 1999.

FIKE. G.D.; SIMMS, D.D.; COCHRAM, R.C. et al. Protein Supplementation of ammoniated wheat sraw: Effect on performance and forage utilization of beef cattle. J. Anim. Sci., v.73, p.1595-1601, 1995.

HAYDOCK, K.P.; SHAW, N.H. The comparative yield method for estimating dry matter yield of pasture. Austr. J. Exp. Agric. Anim. Husb., v.15, p.663-670, 1975.

HELMER, L.G.; BARTLEY, E.E.; DEYOE, C.W. Feed processing. VI. Comparison of starea, urea, and soybean meal as protein sources for lactating dairy cows. J. Dairy Sci., v.53, p.883887, 1970. 


\section{Oliveira et al.}

HODGSON, J. Grazing management science into practice. Essex: Lougman Group UK Ltd., 1990. 203p.

LADEIRA, M.M.; VALADARES FILHO, S.C.; SILVA, J.F.C. et al. Consumo e digestibilidades aparentes totais e parciais de dietas contendo cinco diferentes níveis de concentrado, em novilhos nelore. Rev. Bras. Zootec., v.28, p.395403, 1999.

MERTENS, D.R. Regulation of forage intake. In: FAHEY Jr., G.C. (Ed.) Forage quality, evaluation and utilization. Ohio:American Society of Agronomy, 1994. p.450-493.

MINSON, D.J. Forage in ruminant nutrition. New York: Academic, 1990. 483p.

MOTT, G.O.; LUCAS, H.L. The design, conduct and interpretation of grazing trials on cultivated and improved pastures. In: INTERNATIONAL GRASSLAND CONGRESS, 6., 1952, Pasadena. Proceedings... Pasadena, 1952. p.1380-1385.

OWENS, F.N.; ZINN, R. Metabolismo de la proteina en los ruminants. In: CHURCH, C.D. (Ed.). El ruminante:fisiologia digestiva $y$ nutrición. Zaragoza:Acribia, 1988. 641p.

PARRÉ, C. Utilização da uréia e da zeolita na alimentação de ovinos. 1995. 96f. Tese (Docência Livre) - Faculdade de Ciências Agrárias e Veterinárias, Universidade Estadual Paulista, Jaboticabal, SP.

PAULINO M.F.; DETMAN, E.; ZERVOUDAKIS, J.T. Suplementos múltiplos para recria e engorda de bovinos em pastejo. In: BITTENCOURT, A.; FERREIRA,C.C.B.; FIGUEIREDO, F. C. (Eds.) SIMPÓSIO DE PRODUÇÃO DE GADO DE CORTE. Anais... (2:2001) Viçosa: UFV, DZO, 2001. p.187-232.

PENNING, P.D.; PARSONS, A.J.; ORR, R.J. et al. Intake and behaviour responses by sheep to changes in sward characteristics under continuous stocking. Grass Forage Sci., v.46, p.15-28, 1991.

PRIGGE, E.C.; VARGA, G.A.; VICINI, J.L. et al. Comparison of ytterbium chloride and chromium sesqioxide as fecal indcators. J. Anim. Sci., v.53, p.1629-1633, 1981.
REYNOLDS, C.K. Metabolism of nitrogenous compounds by ruminants liver. J. Nutr., v.122, p.1251-1255, 1992.

ROBERTSON, J.B.; VAN SOEST, P.J. The detergent system of analysis and its application to human foods. In: JAMES, W.P.T.; THEANDER, O. (Eds.). The analysis of dietary fiber in food. New York:Marcel Dekker, 1981. p.123-158.

SALIBA, E.O.S; RODRIGUEZ, N.M.; GONÇALVES, L.C. et al. Effect of corn soybean lignin residues submitted to the ruminal fermentation on structural carbohydrates digestibility. Arq. Bras. Med. Vet. Zootec., v.51, p.85-88, 1999.

SAMPAIO, I.B.B. Estatística aplicada à experimentação animal. Belo Horizonte: Fundação de Ensino e Pesquisa em Medicina Veterinária e Zootecnia, 1998. 221p.

SISTEMA de análises estatísticas e genéticas SAEG. Viçosa: UFV, 1995.

SNFIFEN, C.J.; O'CONNOR, J.D.; VAN SOEST, P.S. et al. A net carbohydrate and protein availability. J. Anim. Sci., v.70, p.35623577, 1992.

THIAGO, L.R.L.S. Suplementação de bovinos em pastejo. In: Curso sobre suplementação mineral em bovinos. Campo Grande:EMBRAPA-CNPGC, 1998. p.50-69.

TILLEY, J.A.; TERRY, R.A. A two stage techinique for the in vitro digestion of forage crops. J. Br. Grassl. Soc., v.18, p.104-111, 1963.

VALADARES FILHO, S.C. Nutrição e avaliação de alimentos e tabelas de composição de alimentos para bovinos. IN: REUNIẪO ANUAL DA SOCIEDADE BRASILEIRA DE ZOOTECNIA, 37., 2000, Viçosa. Anais... Viçosa: SBZ, 2000. p.267-337.

VAN SOEST, P.J. Nutritional ecology of the ruminants. 2.ed. Ithaca: Cornell University, Ithaca. 1994. 476p.

WILLIAMS, C.H.; DAVID, D.J.; ILSMAA, O. The determination of chromic oxide in faeces samples by atomic absorption spectrophotometry. J. Agric. Sci., v.59, p.381385, 1962. 